\title{
Regional Flood Risk Management Modeling and Application
}

\author{
Bojun Liu, ${ }^{1,2, a}$, Jinliang Zhang ${ }^{1,2}$, Libin Yang $^{2}$, Siyu Cai ${ }^{3}$, Dawei Zhang ${ }^{3}$, Fusheng Li $^{2}$ \\ ${ }^{1}$ Yellow River Engineering Consulting Co., Ltd Postdoctoral Programme, Zhengzhou 450003, Henan, China \\ ${ }^{2}$ Yellow River Engineering Consulting Co., Ltd, Zhengzhou 450003, Henan, China \\ ${ }^{3}$ China Institute of Water Resources and Hydropower Research, Beijing 100038, China
}

\begin{abstract}
China is one of the countries with frequent flood disaster, and it does fall often with more precipitation especially from June to October in the Yangtze River, which would very easily cause floods thereby seriously threating to the safety of each region along the Yangtze River. How to manage regional flood risk reasonably and efficiently under the new situation of the joint effects of climatic change and human activities deserves more researches. The regional flood risk management model is built and applied in the Jingjiang section of the Yangtze River to derive regional flood processes under the condition of floodwall break and assess the effects of flood on each factor in the region. The built model is reliable and practical with reasonable results, would support some sort of technical help for regional flood risk management, water resources protection and measure-making of flood prevention and disaster mitigation.
\end{abstract}

\section{Introduction}

Water resources, as one of the most important basic natural resources, are limited in the natural. Due to the restrictive function of climate and geographical conditions, water resources vary greatly in different regions causing the condition of abundant water resources in the south region and scarce water resources in the north region, and the uneven spatial and temporal distribution of water resources, which also has brought great difficulties in the management of water resources in China. In the context of a changing environment with more and more frequent human activities and climate change, the problem of water resources variation has appeared in many regions of China, especially the Yangtze River basin, where floods are frequent with various types and levels of flood risk. In addition, the high frequency, wide range, serious disaster and great economic loss caused by floods seriously threaten the sustainable development of social economy and the safety of people's life and property, and bring great challenges to the work of regional water resources protection and allocation.

In recent years, many researchers used a variety of methods and modelling approaches to study regional flood disaster evaluation, regional flood risk assessment, flood management and the compilation of flood risk maps $^{[1-7]}$, and the complex river network flood evolution process of Jingjiang-Dongting Lake were also studied ${ }^{[8]}$, which have greatly enriched the research results of the flood management. However, there are few studies on regional flood risk management including flood diversion areas. In particular, risk-based flood resource management is an inevitable choice in a changing environment ${ }^{[9]}$. Flood-diversion areas play an important role in regional flood management, and the floodwall break caused by high flow floods greatly increases the risk of flood. How to accurately simulate the flood evolution process and evaluate the flood impact in this situation using the model is worth further research.

Therefore, the flood risk management of the Jingjiang section in the middle and lower reaches of Yangtze River is proposed in this study to simulate the state of flood flow in different flood situations in the region of the floodwall break and analyse the risk in the process of flood routing and risk distribution characteristics and evaluate the influence of the evaluation of regional flood risk. In this way, the risk of flood can be effectively reduced, and the results of this study could play a supplementary role in the formulation of flood control and disaster reduction measures under the new situation, so as to provide effective technical support for regional flood risk management.

\section{Model principles}

The sub-model of flood evolution and flood impact assessment respectively included in the regional flood risk management model is built in the study. In which, the sub-model of flood evolution is coupled of 1D MIKE11 hydrodynamic model and 2D MIKE21 hydrodynamic model based on the characteristics of the Jingjiang section of the Yangtze River; The flood impact assessment model, using the flood submerging range, submerging depth and submerging duration calculated by the flood evolution model, is to establish the curve of water depth and loss ${ }^{[10]}$, and then the effect of flood can be assessed based on the flood disaster assessment (including affected population, total submerging area,

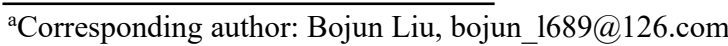


submerging cultivated area and length of submerging road) and the economic loss (including resident property loss, industrial loss, agricultural loss, commerce and trade loss, road loss). The frame of regional flood risk management model is shown in Fig. 1. The affected population is calculated by the following formula ${ }^{[11]}$ :

$$
P_{e}=\sum_{i}^{n} \sum_{j}^{m} A_{i, j} \times d_{i, j}
$$

where, $P_{e}$ is the affected population; $A_{i, j}$ is the submerging area of the $j$-th residential land in the $i$-th administrative unit; $d_{i, j}$ is the population density of the $j$ th residential land in the $i$-th administrative unit; $n$ is the number of administrative divisions; and $m$ is the number of residential land plots.

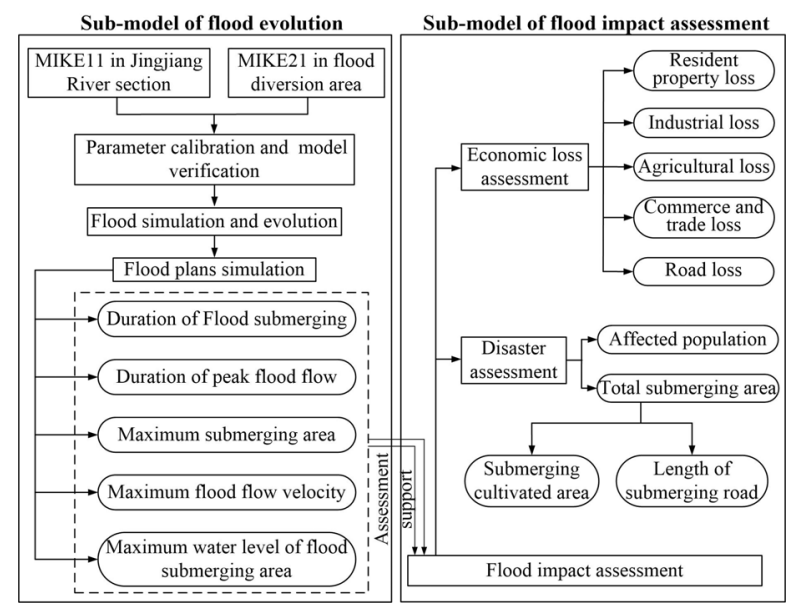

Figure 1. The frame of regional flood risk management model

\section{Modelling and application}

\subsection{Study area}

The Jingjiang section of the Yangtze River, located in the Hubei province, is at the heartland of flood disaster distribution in the Yangtze River basin, and also is the most severe area with flood disaster in the middle and lower reaches of the Yangtze River. The Jingjiang flooddiversion area (JJFDA), surrounding by the Yangtze River in north and east, Ouchi River and Anxiang River in south and Hudu River in west (seen in Fig. 2), is located in the Gongan county $\left(29.50^{\circ} \mathrm{N} \sim 30.38^{\circ} \mathrm{N}\right.$, $111.23^{\circ} \mathrm{E} \sim 112.80^{\circ} \mathrm{E}$ ), and its region altitude decreases from the north to the south.

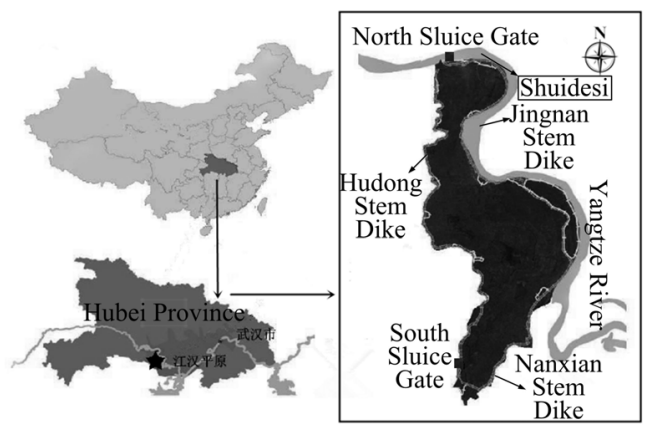

Figure 2. Jingjiang flood-diversion area
The area of the JJFDA is $921.34 \mathrm{~km}^{2}$, with a designed flood storage level of $42.00 \mathrm{~m}$ and an effective flood storage capacity of 5.4 million $\mathrm{m} 3$, which is mainly used to regulate the over-limit flood in the Jingjiang River section, so as to ensure the safety of the Jingjiang floodwall and reduce the flood threat in Wuhan and Dongting Lake areas. The JJFDA is located in a humid region, belonging to the subtropical climate of central and north China, with a lot of rain and concentrated rainfall. The average annual precipitation is $1125 \sim 1190$ $\mathrm{mm}$. The flood season of this region is from May to October, and July and August are the main flood season and the annual precipitation of precipitation stations is $30 \%$ to $55 \%$ in this period. The average annual temperature of the region is $16.2 \sim 16.6^{\circ} \mathrm{C}$, and the average sunshine hours is $1798.3 \sim 1845.7 \mathrm{~h}$ and the annual average wind speed is $2.1 \sim 2.8 \mathrm{~m} / \mathrm{s}$. This region is windy south in summer and northwest in winter. The Jingnan flood control dike of the Yangtze River, Hudong flood control dike and Nanxian dike (seen in Fig. 2) surrounding the JJFDA occurred 15, 17 and 4 times of overflowing between 1884 and 1954, respectively. The joint impacts of climate change and human activities have added many difficulties to regional flood risk management ${ }^{[12]}$.

\subsection{Flood evolution modelling}

There exists many rivers in the Jingjiang River section, and its inflow and outflow conditions are complex thus the characteristics of flood evolution cannot be simulated by a single hydrodynamic model. Therefore, a coupled model of MIKE11 and MIKE21 is employed in this study to simulate the process of flood evolution in the JJFDA ${ }^{[13-14]}$. The JJFDA, Zhicheng-Jianli section of the Yangtze River, Juzhang River, Songzikou-Xinjiangkou section of the Songzi River, Songzikou-Shadaoguan section of the Songzi River, Caixue River, OuchikouKangjiagang section of the Hudu River, OuchikouGuanjiapu section of the Hudu River and TaipingkouSouth sluice gate section of the Ouchi River are included in the study area, in which, the Juzhang River is selected as the confluence. The detailed information is generalized in the Fig. 3. 


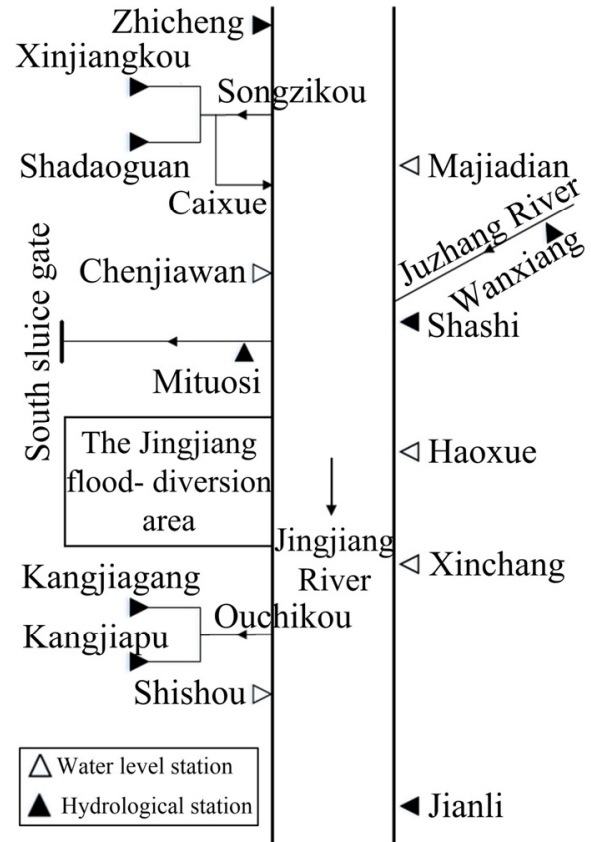

Figure 3. The generalized study area

(1) Grid and section division

The JJFDA is divided into 63601 grids by the triangular grid, with the minimum grid area of $550 \mathrm{~m}^{2}$ and the maximum size of $42659 \mathrm{~m}^{2}$ for MIKE21 model calculation. 143 sections of the Yangtze River are set and 57, 32, 27, and 16 sections are set in the Hudu River, Songzi River, Caixue River and Ouchi River based on the measured data in 2010, respectively, for MIKE11 model calculation. In addition, the initial and boundary conditions of the coupled model needs to be selected. According to the relevant researches ${ }^{[15-16]}$, when the elevation of the grid unit in the JJFDA lower than 33.40 $\mathrm{m}$, the initial water level is $33.40 \mathrm{~m}$ and the initial flow velocity is $0 \mathrm{~m} / \mathrm{s}$; while, when the elevation higher than $33.40 \mathrm{~m}$, the initial water level is valued as the actual elevation and the initial flow velocity is $0 \mathrm{~m} / \mathrm{s}$.

(2) Initial and boundary condition of model

The flow process of the Zhicheng station and the water level process of the Jianli station are selected as the upper and lower boundary condition of MIKE11 model for the watercourse of the Yangtze River; 1818 $\mathrm{m}^{3} / \mathrm{s}, 1300 \mathrm{~m}^{3} / \mathrm{s}$ and $1300 \mathrm{~m}^{3} / \mathrm{s}$ is selected as the inflow boundary condition of the once-in-100 years, once-in200 years and once-in-1000 years flood for the Juzhang River; the relation between water level and flow at the Xinjiangkou station, Shadaoguan station and south sluice gate is selected as the outflow boundary condition of the Songxi River, Songdong River and Hudu River, respectively. The relations between water level and flow at the Kangjiagang and Guangjiapu are taken as the outflow boundary condition of the Ouchi River. In the JJFDA, $44.5 \mathrm{~m}, 45.0 \mathrm{~m}$ and $45.22 \mathrm{~m}$ is selected as the outer boundary condition of the once-in-100 years, oncein-200 years and once-in-1000 years flood, respectively. Especially, the safe region, which can be removed from the JJFDA, is not taken as an internal boundary condition to calculate; the water-blocking function of the central bar in the JJFDA can be neglected; the local grid topography and roughness of the roads, channels and watercourses in the JJFDA need to be modified ${ }^{[17]}$. The results of the grid division in the JJFDA and the section division in the involved rivers are shown in Fig. 4.

(a) Grid division (b) Section division

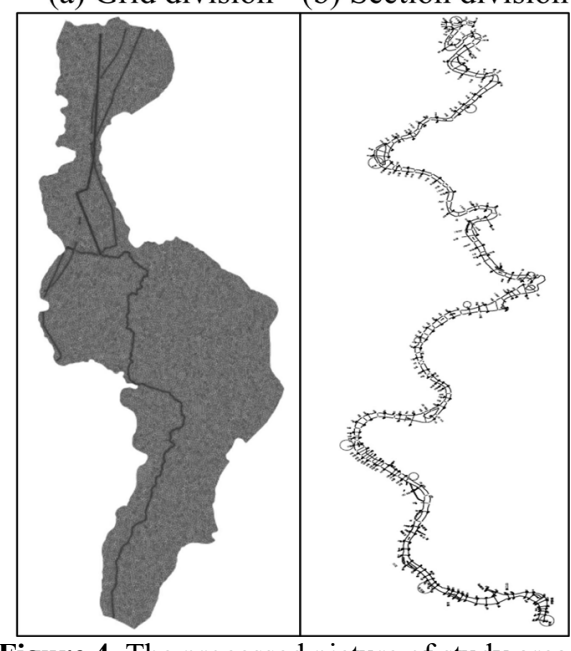

Figure 4. The processed picture of study area

(3) Parameter calibration and model verification

The roughness in the proposed model is calibrated and verified by the measured flood flow and water level data of Shishou, Xinchang, Haoxue, Shashi, Chenjiawan, Majiadian, Zhicheng and Jianli from July 18, 2010 to August 2, 2012 and July 17, 2012 to August 7, 2012. The results show that the maximum water-level and flow-velocity variation of the stations in 2010 is $13.4 \mathrm{~cm}$ and $2.38 \%$; the maximum water-level and flow-velocity variation of the stations in 2012 is $20.0 \mathrm{~cm}$ and $1.20 \%$, respectively. The absolute value of the water level in each station is all within $20 \mathrm{~cm}$, and the relative error of maximum flow velocity all less than $10 \%$, which indicate that the roughness value is reasonable and the proposed model can be used in the simulation for the river network surrounding the JJFDA. The calibrated and verified roughness of the main channel in the ZhichengChenglingji section of the Jingjiang River is 0.020 and its roughness of the marginal bank is 0.025; the roughness of the main channel in the Hudu River, Songzi River, Ouchi River is 0.024 and their roughness of the marginal bank is 0.033 .

Due to the insufficient data of flood diversion operation data in the JJFDA (flood diversion data from July 22, 1954 to August 22, 1954 only exists), which makes the parameter calibration and model verification of the MIKE21 model difficult. Thus, the roughness sensitivity analysis is employed to verify the relative error of the flow velocity at the north sluice gate, and the rationality of submerged area and submerged water depth can be compared with the situation in 1954 so as to verify the reliability of the MIKE21 model ${ }^{[18-19]}$. The result suggests that the relative error of the flow velocity at the north sluice gate is $2.35 \%$, and the submerged area and submerged water depth are within the effective range of the situation in 1954 indicating the roughness value is reasonable and the simulated results are reliable. Therefore, the calibrated and verified roughness of the paddy land, fishpond, dry land, forest land and building 
in the JJFDA is $0.050,0.040,0.065,0.070$ and 0.085 , respectively.

\subsection{Coupling of the flood evolution model and flood impact assessment model}

The simulated characteristics of flood change process by the flood evolution model is used as the coupling point for the flood impact assessment model, that is, the type of input and output is formed to realize data transfer between the models for the modelling of the regional flood risk management.

\subsection{Flood situation selection}

According to the geological condition of the dikes, change of river regime and historical condition in the Jingjiang River section, the Zhenghe village, the electric pumping station named Ershensi, the Shuidesi village located in the dike of the Yangtze River and the Qunyi village located in the dike of the Hudong River are the potential dike breaking places in the JJFDA. In addition, the annual normal water level of the Three Gorges reservoir reaches to $175 \mathrm{~m}$ during 2010 to 2015 making the flood control situation in the JJFDA changed, thus, the once-in-100 years, once-in-200 years and once-in1000 years flood after the Three Gorges reservoir operation are chosen as the flood situation for above potential dike breaking places.

\section{Results and discussion}

\subsection{Flood evolution simulation}

The Shuidesi with the highest probability of dike breaking is used to analyse the flood evolution in the JJFDA. It is assumed that the once-in-100 years, oncein-200 years flood will occur in the Yangtze River and the dike at the Shuidesi will break, thus the flood evolution process can be seen in Fig. 5, in which, Fig. 5 (a) (d) is the water-depth distribution at $10 \mathrm{~h}, 20 \mathrm{~h}, 50$ $\mathrm{h}$ and $110 \mathrm{~h}$ under the once-in-100 years flood; Fig. 5 (e) $\sim$ (h) is the water-depth distribution at $10 \mathrm{~h}, 20 \mathrm{~h}, 50 \mathrm{~h}$ and $90 \mathrm{~h}$ under the once-in-200 years flood, respectively.
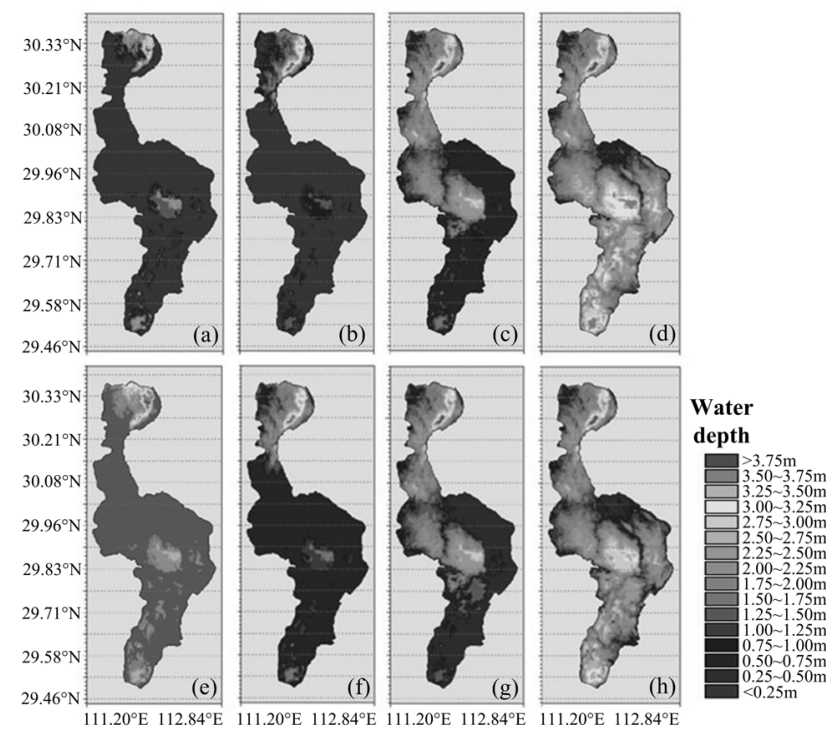

Figure 5. Water-depth distribution of JJFDA under flood

Under the once-in-100 years flood, the duration of flood diversion last for $231 \mathrm{~h}$ and the flood storage volume is $53.96 \times 10^{8}$. Flood flows into the JJFDA through the breaking point of the Shuidesi and is pushed southward, at $10 \mathrm{~h}$, the front of flood reaches to the Xinhong; after $11 \mathrm{~h} \sim 20 \mathrm{~h}$, part of flood is accumulated in the Xinhong and its maximum water depth is $6.0 \mathrm{~m}$, while flood flows to Qinghuasi and then flows to the Huangjinkou rapidly through the narrow contraction section of Majiazui; at $21 \mathrm{~h} \sim 50 \mathrm{~h}$, the flood flows along the line the Luxun Lake and Chonghu Lake, and the maximum water depth in the Chonghu Lake is $5.5 \mathrm{~m}$; after $51 \mathrm{~h} \sim 110 \mathrm{~h}$, flood flows to the Huangtian Lake and then the region in the Gongan county has the higher elevation along the Yangtze River is submerged, while the maximum water depth in the Huangtian Lake is 6.5 $\mathrm{m}$; about 115 hours later, the JJFDA is completely submerged, and the water level will continue to rise if the breaking place cannot be blocked off. Under the once-in-200 years flood, the duration of flood diversion last for $184 \mathrm{~h}$ and the flood storage volume is also $53.96 \times 10^{8}$. Compared to the once-in-100 years flood, at $11 \mathrm{~h} \sim 20 \mathrm{~h}$, the maximum water depth in the Xinhong is $6.5 \mathrm{~m}$ and the duration of completely submerging in the JJFDA is reduced by $20 \mathrm{~h}$. Furthermore, it also can be found that deeper water depth and faster flow velocity is distributed across the entrance of the JJFDA, and there is the steady flow velocity in the regions like Xinhong, Qinghuasi, Chonghu Lake and Huangtian Lake, however, the water depth in above regions, exceeds $6 \mathrm{~m}$, is much higher than the safety water depth of $4.5 \mathrm{~m} \sim 5 \mathrm{~m}$, which inevitably leads to overflow and then poses a high flood risk.

\subsection{Flood impact assessment}

Table 1 and Table 2 show that under different flood situations, the population of each potential dike breaking place is about 500,000 , with a large number of people being affected; due to the dense population in the region, flood disaster would inevitably threaten the safety of people's property once the flood control dike of the 
Jingjiang River break, which brings a large risk to the regional flood management. In addition, the JJFDA would be submerged completely when the dike breaking occurred at the Shuidesi, which suggests the JJFDA would be most heavily affected once the dike at the Shuidesi breaks, and thus this section needs to be protected emphatically. Moreover, the agricultural loss is the most serious due to the significant proportion of agricultural land in the JJFDA and the vulnerability of crops; and most of the industries and service industries in the region are located at the place with the safe elevation, so their losses induced by flood diversion are less than the agricultural loss. Furthermore, there is little loss of roads and railways in the region. In summary, the analysed and discussed results indicate that the flood impact assessment by the proposed model agrees with realistic cases and the models in this study are reliable, practical and reasonable.

Table 1. Assessed results of flood impacts in Shuidesi and Zhenghe village

\begin{tabular}{|c|c|c|c|c|c|c|}
\hline \multirow{2}{*}{ Flood situation (once-in-years flood) } & \multicolumn{3}{|c|}{ Shuidesi } & \multicolumn{3}{|c|}{ Zhenghe village } \\
\hline & 100 & 200 & 1000 & 100 & 200 & 1000 \\
\hline Affected people $\left(10^{4}\right)$ & 50.49 & 50.49 & 50.47 & 48.79 & 49.22 & 50.28 \\
\hline Total submerged area $\left(\mathrm{km}^{2}\right)$ & 893.77 & 893.77 & 893.77 & 857.39 & 866.20 & 889.67 \\
\hline Submerged cultivated area $\left(10^{4} \mathrm{ha}\right)$ & 5.91 & 5.91 & 5.91 & 5.60 & 5.67 & 5.87 \\
\hline Submerged road $(\mathrm{km})$ & 102.43 & 102.43 & 102.43 & 98.01 & 100.20 & 102.43 \\
\hline Submerged railway $(\mathrm{km})$ & 33.27 & 33.27 & 33.27 & 33.27 & 33.27 & 33.27 \\
\hline Loss of residential property (RMB 100 million) & 15.20 & 15.34 & 15.43 & 13.87 & 14.13 & 14.72 \\
\hline Industrial losses (RMB 100 million) & 48.47 & 48.61 & 48.70 & 47.14 & 47.40 & 47.99 \\
\hline Agricultural losses (RMB 100 million) & 27.51 & 27.67 & 27.81 & 25.40 & 25.78 & 26.77 \\
\hline Business and trade losses (RMB 100 million) & 75.98 & 76.28 & 76.51 & 72.54 & 73.18 & 74.76 \\
\hline Road loss (RMB 100 million) & 4.66 & 4.66 & 4.67 & 4.31 & 4.39 & 4.59 \\
\hline
\end{tabular}

Table 2. Assessed results of flood impacts in Ershengsi and Qunyi village

\begin{tabular}{|c|c|c|c|c|c|c|}
\hline \multirow{2}{*}{ Flood situation (once-in-years flood) } & \multicolumn{3}{|c|}{ Ershengsi } & \multicolumn{3}{|c|}{ Qunyi village } \\
\hline & 100 & 200 & 1000 & 100 & 200 & 1000 \\
\hline Affected people $\left(10^{4}\right)$ & 50.25 & 50.02 & 50.26 & 50.30 & 50.31 & 50.32 \\
\hline Total submerged area $\left(\mathrm{km}^{2}\right)$ & 889.06 & 884.17 & 889.42 & 889.74 & 889.81 & 890.47 \\
\hline Submerged cultivated area $\left(10^{4} \mathrm{ha}\right)$ & 5.86 & 5.82 & 5.87 & 5.87 & 5.87 & 5.88 \\
\hline Submerged road $(\mathrm{km})$ & 102.43 & 102.43 & 102.43 & 102.43 & 102.43 & 102.43 \\
\hline Submerged railway $(\mathrm{km})$ & 33.27 & 33.27 & 33.27 & 33.27 & 33.27 & 33.27 \\
\hline Loss of residential property (RMB 100 million) & 14.70 & 14.61 & 14.70 & 14.74 & 14.74 & 14.73 \\
\hline Industrial losses (RMB 100 million) & 47.97 & 47.88 & 47.97 & 48.01 & 48.01 & 48.00 \\
\hline Agricultural losses (RMB 100 million) & 26.74 & 16.60 & 26.74 & 26.79 & 26.80 & 26.81 \\
\hline Business and trade losses (RMB 100 million) & 74.71 & 64.48 & 74.71 & 74.80 & 74.81 & 74.81 \\
\hline Road loss (RMB 100 million) & 4.58 & 4.57 & 4.58 & 4.59 & 4.59 & 4.59 \\
\hline
\end{tabular}

\section{Conclusions}

Flood itself has the peculiarity of risk and uncertainty ${ }^{20-}$ ${ }^{21]}$, for example, once-in-100 years and once-in-200 years may not cause the dike breaking because of the big water quantity with low flow velocity, and the high flow velocity with little water quantity will also lead to the instantaneous breaking of dike causing various problems such as the floating of dike facilities, which tends to make the accurate simulation of flood evolution process and the timely assessment of flood impact both difficult, and thus seriously threatening the regional security. The regional flood risk management model built in the study, can simulate accurately flood flowing process under the situation of dike breaking and assess rapidly various losses induced by flood diversion, is reliable, practical and reasonable, which also can provide the effective supports for the emergency planning of flood control, deployment of flood-relief efforts, flood disaster assessment and joint operation of flood control projects in a regional context.

However, with the rapid development of computer technology, flood risk management is increasingly dependent on runoff forecasting information ${ }^{[22-23]}$. And then, a number of problems can arise, for example, the forecasting flood runoff smaller than the actual value could result in inadequate flood preparation and slow emergency response causing life and property safety under a large risk and a great economic loss; the opposite situation is that the forecasting flood runoff bigger than the actual value could result in ineffective flood control plans causing the waste of human and material resources. Therefore, how to control flood and effectively use rainflood resources under uncertainty and risk based on the joint operation of water conservancy projects is a hot issue and deserves further study in the future.

\section{Acknowledge}

The paper is jointly supported by the National Key R\&D Program of China (2017YFC0404306), the National Natural Science Foundation of China (Gran No. 51509263), and the Yellow River Engineering Consulting Co., Ltd Postdoctoral Programme (YREC2018-PD03). 


\section{References}

1. Nicholls R J, Hoozemans F M J, Marchand M. Increasing flood risk and wetland losses due to global sea-level rise: regional and global analyses[J]. Global Environmental Change, 1999, 9(Suppl 1):S69-S87.

2. Plate E J. Flood risk and flood management[J]. Journal of Hydrology, 2005, 267(1):2-11.

3. Apel H, Aronica G T, Kreibich H, et al. Flood risk analyses - how detailed do we need to be?[J]. Natural Hazards, 2009, 49(1):79-98.

4. Marchi L, Borga M, Preciso E, et al. Characterisation of selected extreme flash floods in Europe and implications for flood risk management[J]. Journal of Hydrology, 2010, 394(12):118-133.

5. Winsemius H C, Beek L P H V, Jongman B, et al. A framework for global river flood risk assessments $[\mathrm{J}]$. Hydrology and Earth System Sciences, 17,5(201305-21), 2013, 17(5):1871-1892.

6. Jain S K, Yoganarasimhan $G$ N, Seth S M. A RISK-BASED APPROACH FOR FLOOD CONTROL OPERATION OF A MULTIPURPOSE RESERVOIR[J]. Jawra Journal of the American Water Resources Association, 2010, 28(6):10371043.

7. Chen S, Yu G. Variable Fuzzy Sets and its Application in Comprehensive Risk Evaluation for Flood-control Engineering System[J]. Advances in Science \& Technology of Water Resources, 2005, 5(2):153-162.

8. Xie Zuotao, Fang Hongwei, Zhong Zhiyu. Research on flood routing in the river nerwork between Jingjiang River and Dongting Lake[J]. Jouranl of Sediment Research, 2010 (6): 38-43.

9. Borgomeo E, Hall J W, Fung F, et al. Risk-based water resources planning: Incorporating probabilistic nonstationary climate uncertainties[J]. Water Resources Research, 2014, 50(8): 6850-6873.

10. BARO SUAREZ J E, DIAZ DELGADO C, ESTELLER ALBERICH $\mathrm{M} \mathrm{V}$, et al. Economic flood loss estimation curves for Mexican rural and residential areas. Part 1: methodology proposal [J]. Ingenieriz Hidraulica en Mexico, 2007, 22(1): 91102.

11. Todorovic P, Rousselle J. Some problems of flood analysis [J]. Water Resource Research, 1971, 7(5): 1144-1150.

12. Downton M W, Morss R E, Wilhelmi O V, et al. Interactions between scientific uncertainty and flood management decisions: Two case studies in Colorado[J]. Global Environmental Change Part B Environmental Hazards, 2005, 6(3):134-146.

13. Jouzdani A, Kabiri-Samani A. Investigations of the Difference in Dam Break Modeling Approaches between 1-D and 2-D Hydrodynamic Model[J]. Applied Mechanics \& Materials, 2011, 90-93:24232426.
14. Chu Q, Peng D, Zongxue X U, et al. Risk analysis of Urban flooding by using MIKE 11 and MIKE 21[J]. Journal of Beijing Normal University, 2014.

15. Soulis J V. COMPUTATION OF 2DIMENSIONAL DAM-BREAK FLOOD FLOWS[J]. International Journal for Numerical Methods in Fluids, 1992, 14(6):631-664.

16. Huang Jinchi, He Xiaoyan. Unified 2-D numerical model for simulating dam break wave propagation $[\mathrm{J}]$. Journal of Hydraulic Engineering, 2006, 37(2) : 222-226.

17. $\mathrm{Xu}$ T. Calculation Principle and Application Example of a Two-dimensional Flow ModelMIKE21 HD[J]. Port Engineering Technology, 2010.

18. Guo F, Hanfei Q U, Zeng H, et al. Flood Routing Numerical Simulation of Flood Storage Area Based on MIKE21 FM Model[J]. Water Resources \& Power, 2013.

19. Zolghadr M, Hashemi M R, Zomorodian S M A. Assessment of MIKE21 model in dam and dikebreak simulation[J]. Iranian Journal of Science \& Technology Transaction B Engineering, 2011, 35:247-262.

20. Ashkar D R. Seasonality of flooding and the assessment of flood risk [J]. Proc.Inst.Civ.Eng., 1981,70: 1023-1035.

21. Futter M R, Mawdsley A V. Short-term flood risk prediction: a comparison of the cox regression model and a distribution model [J]. Water Resource Research, 1991, 27(7): 1649-1656.

22. Ding $\mathrm{W}$, Zhang $\mathrm{C}$, Peng $\mathrm{Y}$, et al. An analytical framework for flood water conservation considering forecast uncertainty and acceptable risk[J]. Water Resources Research, 2015, 51(6):4702-4726.

23. Hurlbert M, Gupta J. Adaptive Governance, Uncertainty, and Risk: Policy Framing and Responses to Climate Change, Drought, and Flood[J]. Risk Analysis, 2016, 36(2):339-356. 